\title{
Reported food intake and distribution of body fat: a repeated cross-sectional study Benno Krachler*1,2, Mats Eliasson ${ }^{3,4}$, Hans Stenlund ${ }^{5}$, Ingegerd Johansson ${ }^{6}$, Göran Hallmans ${ }^{7}$ and Bernt Lindahl ${ }^{2}$
}

\begin{abstract}
Address: ${ }^{1}$ Department of Medicine, Kalix Hospital, Kalix, Sweden, ${ }^{2}$ Behavioural Medicine, Public Health and Clinical Medicine, Umeå University, Umeå, Sweden, ${ }^{3}$ Department of Medicine, Sunderby Hospital, Luleå, Sweden, ${ }^{4}$ Medicine, Public Health and Clinical Medicine, Umeå University, Umeå, Sweden, ${ }^{5}$ Epidemiology and Public Health Sciences, Umeå University, Umeå, Sweden, ${ }^{6}$ Odontology, Cariology, Umeå University, Umeå, Sweden and ${ }^{7}$ Nutrition Research, Public Health and Clinical Medicine, Umeå University, Umeå, Sweden

Email: Benno Krachler* - benno.krachler@medicin.umu.se; Mats Eliasson - Mats.Eliasson@nll.se; Hans Stenlund - hans.stenlund@epiph.umu.se; Ingegerd Johansson - Ingegerd.Johansson@odont.umu.se; Göran Hallmans - goran.hallmans@nutrires.umu.se; Bernt Lindahl - bernt.lindahl@medicin.umu.se

* Corresponding author
\end{abstract}

Published: 22 December 2006

Nutrition Journal 2006, 5:34 doi:10.1 186/1475-289/-5-34

This article is available from: http://www.nutritionj.com/content/5/I/34

(c) 2006 Krachler et al; licensee BioMed Central Ltd.

This is an Open Access article distributed under the terms of the Creative Commons Attribution License (http://creativecommons.org/licenses/by/2.0), which permits unrestricted use, distribution, and reproduction in any medium, provided the original work is properly cited.
Received: 23 September 2006

Accepted: 22 December 2006

\begin{abstract}
Background: Body mass, as well as distribution of body fat, are predictors of both diabetes and cardiovascular disease. In Northern Sweden, despite a marked increase in average body mass, prevalence of diabetes was stagnant and myocardial infarctions decreased. A more favourable distribution of body fat is a possible contributing factor.
\end{abstract}

This study investigates the relative importance of individual food items for time trends in waist circumference $(\mathrm{WC})$ and hip circumference $(\mathrm{HC})$ on a population level.

Methods: Independent cross-sectional surveys conducted in 1986, 1990, 1994 and 1999 in the two northernmost counties of Sweden with a common population of 250000. Randomly selected age stratified samples, altogether 2982 men and 3087 women aged 25-64 years. Questionnaires were completed and anthropometric measurements taken. For each food item, associations between frequency of consumption and waist and hip circumferences were estimated. Partial regression coefficients for every level of reported intake were multiplied with differences in proportion of the population reporting the corresponding levels of intake in 1986 and 1999. The sum of these product terms for every food item was the respective estimated impact on mean circumference.

Results: Time trends in reported food consumption associated with the more favourable gynoid distribution of adipose tissue were increased use of vegetable oil, pasta and $1.5 \%$ fat milk. Trends associated with abdominal obesity were increased consumption of beer in men and higher intake of hamburgers and French fried potatoes in women.

Conclusion: Food trends as markers of time trends in body fat distribution have been identified. The method is a complement to conventional approaches to establish associations between food intake and disease risk on a population level. 


\section{Background}

The global trend of increasing obesity in the developed world and, even more pronounced in the countries of transition, is associated with an increase in prevalence of all components of the metabolic syndrome. Based on these observations, predictions of a world-wide epidemic of diabetes have been made. Accumulating evidence for effective preventive intervention [1-3] highlights the importance of early indicators for identifying high-risk individuals. Recent studies have shown that the distribution of body-fat, independent of body mass index (BMI) is an important predictive factor for the development of diabetes.

Waist circumference (WC), as a measure of visceral fat, is more closely associated with diabetes and cardiovascular disease and total mortality than adipose tissue in other regions of the body [4-10]. On the contrary, hip circumference (HC) has been found to be independently associated with lower insulin resistance, lower prevalence and incidence of diabetes and lower total mortality [11-15].

In order to identify predictive markers and potential causative mechanisms of diabetes, associations of sociodemographic and lifestyle factors with body-fat distribution have been investigated. High intake of saturated fatty acids and food patterns with a high glycaemic load have been associated with central obesity. Smoking, a sedentary life-style, and high intake of alcohol are also associated with abdominal obesity whereas physical activity is associated with gynoid fat distribution and higher insulin sensitivity [16-22].

Between 1986 and 1999 body mass in the MONICA population of Northern Sweden increased in both sexes. However, there was no corresponding increase in prevalence of diabetes and the number of myocardial infarctions decreased. During the same period average hip circumference increased markedly, while waist circumference only increased marginally. Concurrent time trends in reported food intake included a less frequent use of $3 \%$ fat milk while $1.5 \%$ milk, low fat margarine and cooking oil became more important. Consumption of oil as dressing, pasta, beer and convenience foods increased markedly. [23-26].

Our hypothesis is that some of the observed time trends in food intake contributed to a more favourable distribution of body-fat, thus compensating for the diabetogenic effects of increased body weight. These trends may also be associated with the sharp decrease of myocardial infarctions in the area. The aim of the present study is to investigate the effect of trends in reported intake of individual food items on concurrent differences in distribution of body-fat measured between 1986 and 1999 on a population level.

\section{Methods}

The MONICA project (Multinational Monitoring of Trends and Determinants in Cardiovascular Disease) was initiated by WHO and included 38 populations in 25 countries. Trends in cardiovascular mortality, coronary heart disease and cerebrovascular morbidity were measured in order to assess the extent to which these trends were related to changes in known risk factors, daily living habits and health care $[27,28]$.

\section{Study design}

The Northern Sweden MONICA Project was performed in the counties of Västerbotten and Norrbotten. Descriptions of the survey procedures and quality assessment of the collected data have been published elsewhere $[29,30]$. In short, the surveys were performed in 1986, 1990, 1994 and 1999 in the period of January to April. The samples for the second, third and fourth surveys were selected irrespective of whether individuals had been selected in previous surveys. From a continuously updated population registry, 250 men and 250 women in each of the age groups 25-34, 35-44, 45-54 and 55-64 years were randomly selected and invited to participate. The target population was approximately 265000 subjects (Fig 1). The participants were invited to the closest health center for a physical examination including anthropometrical measurements and blood sampling. All measurements were performed by specially trained teams of health professionals. Participants were asked to complete a questionnaire on health, socio-economic status and daily living habits. Usual dietary intake over the past year was assessed through a validated, semi-quantitative, self-administered food frequency questionnaire (FFQ)[31]. The questionnaire included 81 items in 1986, 49 items in 1990, and 84 items in 1994 and 1999. 73 items were identical in 1986 and 1999; these are used in the present analysis. Standard portion sizes were used for the estimation of consumed quantities.

\section{Statistical analysis}

A three-step procedure was employed. (i) First, utilizing data from all four surveys, the association between individual food items and waist or hip circumference is estimated, adjusting for age, BMI and survey year. (model 1) In an additional model, smoking status (never/former/ current), physical activity (lower/higher), alcohol consumption (quartiles) and education (primary/secondary/ university) were added as additional covariates. Adjustments were also made for the interaction between high reported level of alcohol consumption and low physical activity, high reported level of alcohol consumption and smoking as well as low level of physical activity and smok- 


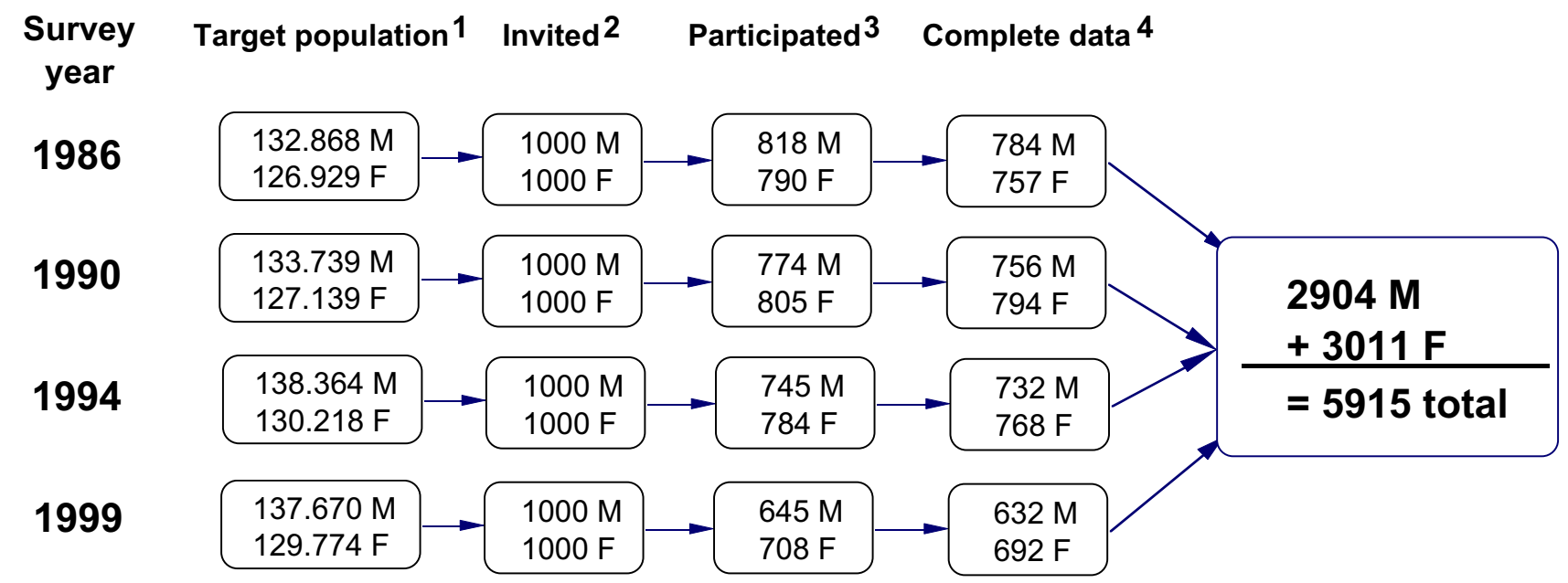

Figure I

Study design. 'Counties of Norrbotten and Västerbotten, population register of inhabitants aged 25-64 on January Ist of the survey-year. ${ }^{2}$ Randomly selected samples of 250 in age strata $25-34,35-44,45-54,55-64$ years. ${ }^{3}$ Number of individuals who appeared at the health centers for measurements and completed FFQ. ${ }^{4}$ Number of individuals with complete anthropometrical data and at least $90 \%$

ing. (model 2) In both models, the level of intake reported most frequently in 1986 was chosen as reference category. As illustrated in table 1, a linear regression model yielded partial regression coefficients for each level of intake. These coefficients represent the association of each level of intake with mean HC or WC compared to the reference level across all survey years and adjusted for covariates. Had the whole population reported the reference level in 1986 and, e.g. level 1 in 1999, the partial regression coefficient of level 1 would represent the difference in mean WC or HC attributable to this time trend in reported intake. Since different proportions of the population reported one of the 8 levels of intake in 1986 and 1999, two further steps are necessary. (ii) Secondly, differences in proportion of the population reporting specific intake levels between the first survey in 1986 and the last one in 1999 are calculated separately for each food item.

(iii) Finally, intake-level specific partial regression coefficients for each food item are multiplied with difference in proportions of population reporting that specific level of intake in 1986 and 1999, respectively. The sum of these product terms for each separate food item is the estimated net effect of time trends in reported food frequency on WC and HC.

(i) Association levels of intake to circumference: $\mathrm{HC}$ or $\mathrm{WC}=\mathrm{a}+\beta_{\text {level } 1}+\beta_{\text {level } 2}+\ldots+\beta_{\text {level } 8}+$ covariates (ii) Differences in proportions of the population reporting respective intake levels:

Proportion in level 1 (1999) - proportion in level 1 $(1986)=\Delta_{\text {level } 1}$;

Proportion in level 2 (1999) - proportion in level 1 $(1986)=\Delta_{\text {level } 2} ;$

Proportion in level 8 (1999) - Proportion in level 8 $(1986)=\Delta_{\text {level } 8}$

(iii) Net effect of time trends in intake on mean HC or WC: $\left(\Delta_{\text {level1 }} * \beta_{\text {level1 }}+\Delta_{\text {level2 }} * \beta_{\text {level2 }}+\ldots+\Delta_{\text {level8 }} * \beta_{\text {level8 }}\right)$

To estimate the combined effect of food-item associated time trends we subtracted mean differences in waist circumference (negatively associated with diabetes and cardiovascular disease) from mean differences in hip circumference (positively associated). Positive values will thus indicate risk-lowering trends in body fat distribution.

Significance of association between reported food-intake and WC or HC was estimated by testing the hypothesis that the partial regression coefficients for different levels of reported intake of a food item were equal and equal to zero $\left(\beta_{\text {level } 1}=\beta_{\text {level2 }}=\ldots=\beta_{\text {level } 8}=0\right)$. To avoid giving a fragmented picture, all food items with large estimated net 
Table I: Example of calculation: Estimated effect of time trend in reported intake of pasta 1986-99 on mean hip-circumference in men:

\begin{tabular}{|c|c|c|c|c|c|}
\hline \multirow[b]{2}{*}{ Reported intake frequency } & \multirow[b]{2}{*}{ level } & \multicolumn{2}{|c|}{ (ii) $\Delta_{\text {levell-8 }}$} & \multirow[b]{2}{*}{$\begin{array}{l}\text { (i) partial regression } \\
\text { coefficients } \beta_{\text {levell-8 }}{ }^{2}\end{array}$} & \multirow[b]{2}{*}{$\begin{array}{l}\text { (iii) Estimated effect on mean } \\
\text { HC: } \Sigma\left(\Delta_{\mathrm{i}}^{*} \beta_{\mathrm{i}}\right) \mathrm{i}=\text { level I-8 }\end{array}$} \\
\hline & & Proportion I999। & Proportion 19861 & & \\
\hline Never & 1 & $(3 / 63)-$ & $7 / 777)^{*}$ & -5.7 & $=0.024 \mathrm{~mm}$ \\
\hline I/year & 2 & $(19 / 631)-$ & $59 / 777)^{*}$ & -5.4 & $=0.247 \mathrm{~mm}$ \\
\hline I-3/month & 3 & $|27 / 63|$ & $408 / 777$ & \multicolumn{2}{|c|}{ reference category ${ }^{3}$} \\
\hline I/week & 4 & (243/63) - & $262 / 777)^{*}$ & -0.2 & $=-0.010 \mathrm{~mm}$ \\
\hline 2-3/week & 5 & $(199 / 631$ - & $40 / 777)^{*}$ & 4.3 & $=1.135 \mathrm{~mm}$ \\
\hline 4-5/week & 6 & $(31 / 631-$ & $\mathrm{I} / 777)^{*}$ & 7.8 & $=0.373 \mathrm{~mm}$ \\
\hline I/day & 7 & $(8 / 63)-$ & 0/777)* & 10.6 & $=0.134 \mathrm{~mm}$ \\
\hline $2-3 /$ day & 8 & $(1 / 631)-$ & $0 / 777)^{*}$ & 13.4 & $=0.021 \mathrm{~mm}$ \\
\hline total & & & & & $\mathrm{I}, 925 \mathrm{~mm}$ \\
\hline
\end{tabular}

\footnotetext{
Inumber of valid answers reporting specific number of intakes divided by total number of valid answers in respective survey-year.

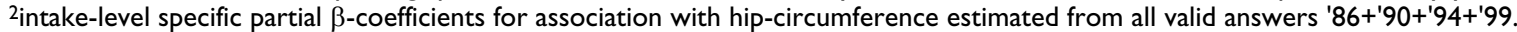
${ }^{3}$ Level 3 is the reference category and therefore not included in the calculation.
}

effects are reported rather than only items with significant estimated associations.

The basic model (i) contains observations from four different cross-sectional surveys conducted over a period of 13 years. During such a long period of time there may be population-wide changes in living conditions and reporting that are difficult to measure and adjust for separately. To avoid these potential biases we adjusted for survey year. Without that adjustment, differences in measured distribution of body-fat would (falsely) be attributed to any concurrent time trend in reported food intake. e.g. if due to improved public transport average walking distance to arrive at work or school was reduced between 1986 and 1999 this change might result in increase in average waist circumference. During the same period of time most people increased their intake of hamburgers. Without adjustment for survey year our model would attribute some of the resulting increase in WC to that concurrent time trend in food habits.

The Statistical Analysis System (SAS for Windows, version 9.1, SAS Institute, Carry, NC 27513, USA) was used for statistical evaluations.

Non-responders got a second letter of invitation 2 weeks after the date for their initial health examination. Telephone-interviews conducted with non-participants indicate a higher percentage of smokers and a lower (selfreported) body weight in that group [30]. Overall dropout rate was about 24\% (1931/8000) [26]. In the present study another 152 individuals had to be excluded due to lack of data for estimation of total energy intake $(<90 \%$ answers in FFQ) and body mass index. These excluded individuals had a higher mean age in men. There was no significant difference with remaining study subjects in other parameters. All participants signed an informed consent form. The Research Ethics Committee of Umeå University approved the study.

\section{Results}

Reported energy intake from different sources, sociodemographic and anthropometrical characteristics of the study population are given in table 2. The decrease in waist-hip ratio was mainly due to a marked increase in hip circumference in both men and women. Smoking became less common, reported energy intake from saturated fatty acids decreased, and intake of alcohol increased. Higher education became more common.

A complete list of food items that were covered by questionnaires is given in the appendix (additional file 1: List of items on food-frequency questionnaires). Out of these, 15 items are shown that were associated with the 10 largest differences in distribution of body fat in either men or women.

Table 3 summarizes time trends in food consumption associated with the largest differences of waist- and hip circumference for women. Increased use of (vegetable) oil and pasta as well as reduced consumption of fruit creams and $3 \%$ fat milk were all associated with reduction of waist circumference. Growing popularity of hamburgers, French fried potatoes and soft drinks were associated with an increase of waist circumference. Increased hip circumference was associated with higher consumption of pasta, vegetable oil as well as cream and $1.5 \%$ milk. Time trends for hamburgers and French fried potatoes went along with minor reductions of hip circumference. Adjustment for other lifestyle-factors attenuated the net effect of time trends in reported food consumption but, did not alter their directions. Only the protective effects of lower con- 
sumption of $3 \%$ milk and added sugar were reduced markedly. The net effect of increased consumption of $4 \%$ beer was reversed.

Figure 2 illustrates associations of food items with differences in both average hip- and waist-circumference in women. Time trends for vegetable oil, pasta, fruit creams and cream were associated with risk-lowering anthropometric time trends, whereas trends for hamburgers and French fried potatoes correlated with risk-increasing trends.

In men, time trends for vegetable oil, pasta and milk were associated with both, largest increase of hip-circumference and largest reduction of waist-circumference (Table 4 , Figure 3). Increased use of hamburgers and potato chips were associated with an increase of average waist circumference but also a positive effect on hip circumference. Only rising consumption of $4 \%$ beer was associated with both, HC decrease and WC increase.

After adjustment for lifestyle-variables (Table 4, model 2) the waist reducing effect of time trends in pasta consumption disappeared whereas the effect of increased consumption of wine was reversed. The negative net-effect of French fried potatoes could also be explained by associated lifestyle.

In general, waist circumference was more responsive in women whereas hip and waist circumferences were equally affected in men.

\section{Discussion \\ Method}

This way of analyzing data derived from food frequency questionnaires is not entirely new. Changes in food habits over time have been expressed in change of waist circumference, before[22]. However, the use of this method in a repeated cross-sectional context is new. The hypothesis that inspired the somewhat cumbersome methodology of this study is: Reported level of intake of a food item is a marker of lifestyle, rather than a measurement of nutrient intake. Therefore, every level of reported intake had to be utilized as a separate variable. This avoids issues of nonlinearity that might arise when categorical variables are converted into continuous ones. The results reflect the association between a marker (reported frequency of intake for one single food item) and objective measurements (waist/hip circumferences) adjusted for other objective measurements (sex, age, BMI, survey year). In the crude model no other food-related markers, such as total reported food intake or reported intake of other food items, are introduced. Thus, adding up different markers (food groups) or adjusting one marker for another (adjusting for reported intake of other foods) - common procedures in similar studies that introduce uncontrollable biases - is avoided (model 1). However, in a separate model lifestyle-markers such as, self reported physical activity, education, smoking status and alcohol consumption are considered as additional explanatory variables (model 2).

Thus, the calculated association may represent more than the effect of a single food item: Related food habits, and

Table 2: Characteristics of study population, 1986 vs. 1999

\begin{tabular}{|c|c|c|c|c|c|c|}
\hline & \multicolumn{3}{|c|}{ Men } & \multicolumn{3}{|c|}{ Women } \\
\hline & $1986(n=784)$ & $1999(n=632)$ & $P^{\prime}$ & $1986(n=757)$ & $1999(n=692)$ & $\mathrm{P}^{\prime}$ \\
\hline Age $(y)$ & $45.0 \pm 11$ & $45.7 \pm 11$ & 0.25 & $44.6 \pm 11$ & $45.7 \pm 11$ & 0.07 \\
\hline Primary education only $(\%)^{2}$ & 58 & 22 & $<0.001$ & 54 & 18 & $<0.001$ \\
\hline Sedentary $(\%)^{2,3}$ & 59 & 66 & 0.01 & 56 & 78 & $<0.001$ \\
\hline Smokers (\%) ${ }^{2,4}$ & 34 & 18 & $<0.001$ & 31 & 24 & 0.003 \\
\hline Intake of alcohol $(\mathrm{g} / \mathrm{d})$ & $2.7 \pm 2.6$ & $3.7 \pm 5.4$ & $<0.001$ & $1.3 \pm 1.4$ & $2.0 \pm 1.6$ & $<0.001$ \\
\hline BMI $\left(\mathrm{kg} / \mathrm{m}^{2}\right)$ & $25.6 \pm 3.5$ & $26.6 \pm 3.4$ & $<0.001$ & $25.0 \pm 4.4$ & $25.9 \pm 4.5$ & $<0.001$ \\
\hline Waist circumference $(\mathrm{cm})$ & $93.0 \pm 9.6$ & $94.9 \pm 9.8$ & $<0.001$ & $85.3 \pm 12.4$ & $84.0 \pm 12.0$ & $<0.004$ \\
\hline Hip circumference $(\mathrm{cm})$ & $97.9 \pm 6.1$ & $103.1 \pm 6.5$ & $<0.001$ & $98.5 \pm 8.8$ & $103.0 \pm 8.6$ & $<0.001$ \\
\hline Waist-to-hip ratio & $0.95 \pm 0.06$ & $0.92 \pm 0.07$ & $<0.001$ & $0.86 \pm 0.07$ & $0.81 \pm 0.07$ & $<0.001$ \\
\hline Energy from alcohol (\%) & $\mathrm{I} . \mathrm{I} \pm \mathrm{I} . \mathrm{I}$ & $\mathrm{I} .5 \pm \mathrm{I} .4$ & $<0.001$ & $0.6 \pm 0.7$ & $0.8 \pm 0.7$ & $<0.001$ \\
\hline Energy from fat (\%) & $38.5 \pm 5.7$ & $37.0 \pm 6.0$ & $<0.001$ & $37.8 \pm 5.7$ & $36.2 \pm 6.1$ & $<0.001$ \\
\hline Energy from saturated fat (\%) & $17.3 \pm 3.2$ & $15.4 \pm 3.1$ & $<0.001$ & $16.7 \pm 3.1$ & $14.6 \pm 3.2$ & $<0.001$ \\
\hline NSP intake $(g / M J)^{5}$ & $2.2 \pm 0.5$ & $2.3 \pm 0.6$ & 0.06 & $2.4 \pm 0.6$ & $2.5 \pm 0.7$ & $<0.002$ \\
\hline Reported intake $(M J / d)$ & $7.6 \pm 2.4$ & $7.5 \pm 2.5$ & 0.80 & $7.0 \pm 2.1$ & $7.4 \pm 2.0$ & $<0.003$ \\
\hline
\end{tabular}

'Education, physical activity and smoking status: Chi-square test for categories, all other two tailed t-test for difference between means

2Education, physical activity and smoking status as percentage of same-sex population, all other values are $x \pm S D$

${ }^{3}$ Less then I hour of strenuous physical activity per week

4 Including recent (<6 month) ex-smokers, since FFQ covered past 12 months

${ }^{5}$ Non-Starch-Polysaccharides $=$ dietary fibre 
Table 3: Food items associated with largest estimated effect on mean waist- and hip-circumference in women.

\begin{tabular}{|c|c|c|c|c|c|c|c|c|c|c|c|c|}
\hline \multirow{3}{*}{$\begin{array}{l}\text { Women } \\
\text { Food item }\end{array}$} & \multirow{2}{*}{\multicolumn{2}{|c|}{ Difference in mean intake 1986-99 }} & \multicolumn{4}{|c|}{$\begin{array}{l}\text { Estimated effect on mean waist } \\
\text { circumference }\end{array}$} & \multicolumn{4}{|c|}{$\begin{array}{l}\text { Estimated effect on mean hip } \\
\text { circumference }\end{array}$} & \multirow{3}{*}{$\begin{array}{c}\text { Combinec } \\
\mathrm{I}^{2} \\
\mathrm{~mm}^{6}\end{array}$} & \multirow{3}{*}{$\frac{2^{3}}{\mathrm{~mm}^{6}}$} \\
\hline & & & \multicolumn{2}{|c|}{ Model $2^{3}$} & \multicolumn{2}{|c|}{ Model $2^{3}$} & \multicolumn{2}{|c|}{ Model I'2 } & \multicolumn{2}{|c|}{ Model $2^{3}$} & & \\
\hline & $/ \mathrm{mo}^{4}$ & $/ 286^{5}$ & $\mathrm{~mm}^{6}$ & $P^{7}$ & $\mathrm{~mm}^{6}$ & $P^{7}$ & $\mathrm{~mm}^{6}$ & $P^{7}$ & $\mathrm{~mm}^{6}$ & $P^{7}$ & & \\
\hline beer, $4 \%$ alcohol & 0.6 & $153 \%$ & -1.10 & 0.60 & -0.92 & 0.83 & -0.68 & 0.59 & -1.24 & 0.36 & 0.42 & -0.32 \\
\hline bread, crisp & -13.4 & $-27 \%$ & -0.31 & 0.21 & -0.37 & 0.26 & 0.06 & 0.65 & -0.09 & 0.64 & 0.37 & 0.28 \\
\hline cream/crème fr $\beta$ iche/sour cream & 1.4 & $40 \%$ & -1.27 & 0.26 & -0.94 & 0.32 & 1.38 & 0.01 & 0.99 & 0.09 & 2.65 & 1.93 \\
\hline fruit soups/fruit creams & -1.3 & $-36 \%$ & -3.24 & 0.01 & -3.13 & 0.02 & -0.07 & 0.58 & -0.25 & 0.67 & 3.17 & 2.88 \\
\hline hamburger & 0.8 & $73 \%$ & 3.21 & 0.07 & 2.94 & 0.13 & -0.66 & 0.47 & $-0.4 I$ & 0.67 & -3.87 & -3.34 \\
\hline milk, I.5\% fat & 18.0 & $331 \%$ & -1.11 & 0.02 & -0.76 & 0.03 & 1.24 & 0.48 & 0.98 & 0.45 & 2.35 & 1.75 \\
\hline milk, $3 \%$ fat & -21.8 & $-84 \%$ & -1.47 & 0.25 & -0.75 & 0.38 & -0.05 & 0.44 & -0.74 & 0.55 & 1.42 & 0.01 \\
\hline oil, cooking & 8.7 & $693 \%$ & -6.18 & $<.01$ & -4.86 & $<.01$ & 1.35 & 0.40 & 0.23 & 0.75 & 7.53 & 5.09 \\
\hline oil, dressing & 3.3 & $210 \%$ & -2.54 & 0.07 & -1.96 & 0.17 & 0.50 & 0.73 & 0.03 & 0.79 & 3.04 & 1.99 \\
\hline pasta & 4.2 & $132 \%$ & -2.21 & 0.25 & -1.47 & 0.45 & 2.14 & 0.09 & 1.61 & 0.15 & 4.35 & 3.09 \\
\hline potato chips/popcorn/salted nuts & 1.5 & $188 \%$ & -0.78 & 0.44 & -0.24 & 0.45 & 1.15 & 0.59 & 1.14 & 0.53 & 1.94 & 1.38 \\
\hline potatoes, French fried & 0.9 & $95 \%$ & 2.11 & 0.14 & 1.90 & 0.13 & -0.42 & 0.05 & 0.04 & 0.13 & -2.52 & -1.86 \\
\hline soft drinks & 1.9 & $93 \%$ & 2.11 & 0.19 & 2.00 & 0.23 & 0.31 & 0.91 & 0.57 & 0.77 & -1.81 & -1.43 \\
\hline sugar/honey in tea/coffee & -10.4 & $-36 \%$ & -0.30 & 0.39 & 0.02 & 0.41 & 0.13 & 0.68 & -0.05 & 0.83 & 0.44 & -0.08 \\
\hline wine & 0.7 & $65 \%$ & -1.03 & 0.05 & -0.83 & 0.08 & 1.08 & 0.15 & 1.67 & 0.22 & 2.11 & 2.51 \\
\hline
\end{tabular}

'Estimate of total effect on diabetes risk: Differences in mean hip-circumferences (negatively associated with DM) - Differences in mean waist-circumferences (positively associated with DM)

2Model I: regression of change in mean reported food frequency on waist/hip circumference adjusted for BMI, age and survey-year.

3 Model 2: all variables are adjusted for BMI, age, survey-year, smoking-status (never/ex-/current), level of reported physical activity (lower/higher), educational level (primary school/secondary school/

college), level of reported alcohol (quartiles) intake as well as interaction between smoking and low physical activity, smoking and high alcohol intake, low physical activity and high alcohol intake.

number of reported intakes per month

relative changes in \% of mean reported intake 1986

${ }^{6}$ estimated net effects of trends in reported intakes on mean waist/hip circumference.

${ }^{7}$ probabilities that partial regression coefficients for different levels of intake are equal to zero at $95 \%$ level 


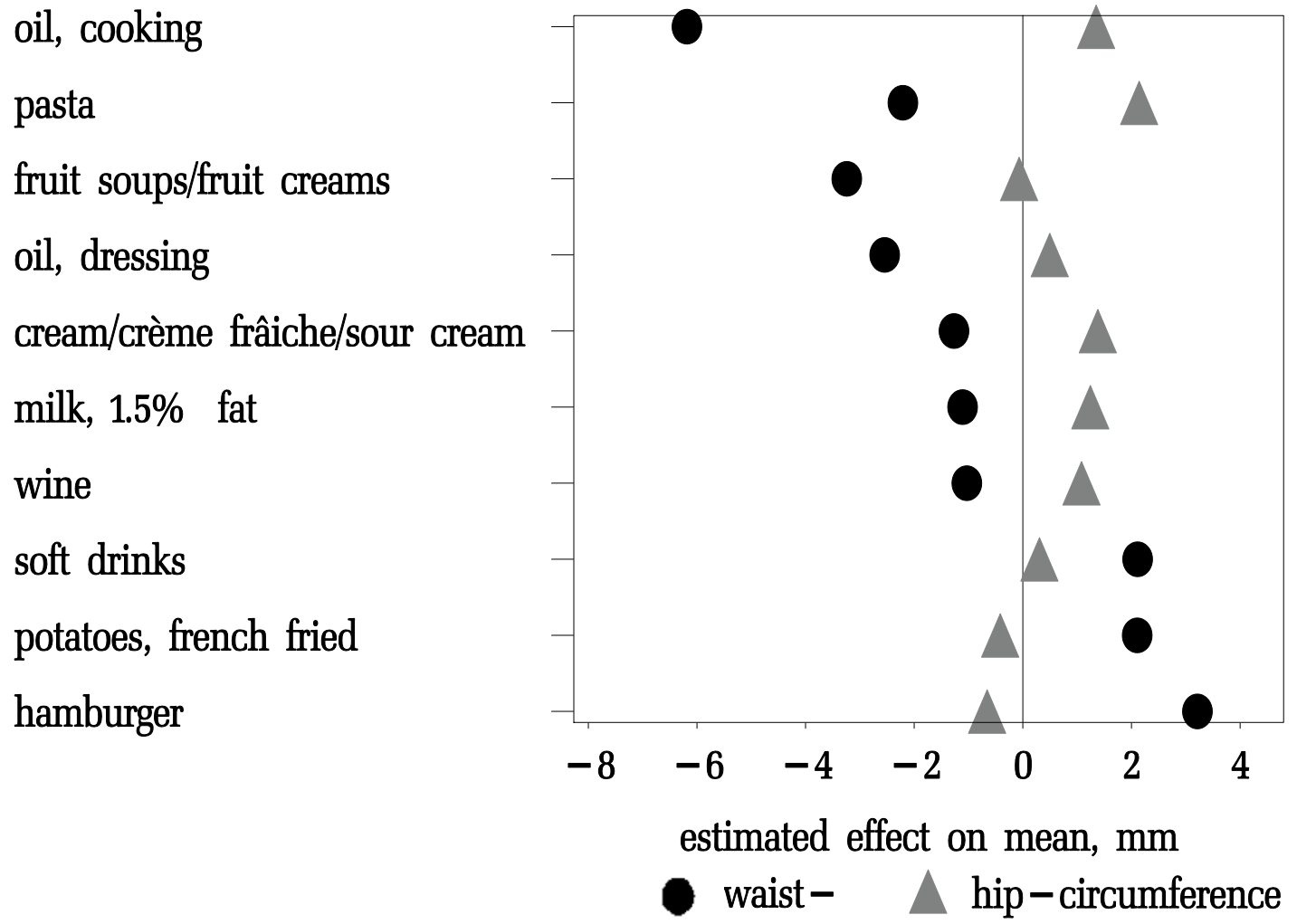

\section{Figure 2}

Estimated effect of time trends in reported food intake 1986-1999 on average waist- and hip-circumference in women. 10 items with the largest estimated effect on distribution of body fat in women. Sort order is the sum of effects from largest reduction to highest increase of risk for diabetes. The underlying associations between food intake and waist- and hipcircumferences were adjusted for age, body-mass and survey year (model I)

possibly a connected general lifestyle have to be considered as potential causative factors.

This is an ecological study based on four independent randomly selected samples from the same population. An apparent weakness, compared to a prospective cohort design, is that some of what is measured as change over time might be an effect of studying different samples. However, the size of the samples chosen should limit that risk. On the other hand, a repeated cross sectional study might tell us more about time trends in a specific population since new samples reflect social changes, such as the marked increase in average education in our population.

\section{Results}

Main trends in reported food consumption associated with a more favourable distribution of body fat were increased use of (vegetable) oil, pasta, 1.5\% milk and reduced consumption of $3 \%$ milk. Time trends associated with high-risk fat distribution were increased consumption of hamburgers and soft drinks.

To our knowledge, this is the first study of association between time trends in reported intake of individual food items and waist- and hip- circumferences on a population level. Previous studies were either focussed on macronutrients [32,33] or food patterns [34,35], or did not address differential effects on hip- and waist circumferences. Moreover, this study gives a comprehensive picture of a geographically defined population. Thus, our results may complement data derived from cohorts selected by age or profession. In contrast to many other studies, all anthropometrical measurements were made by personnel trained according to standardized criteria. 
Table 4: Food items associated with largest estimated effect on mean waist- and hip-circumference in men.

\begin{tabular}{|c|c|c|c|c|c|c|c|c|c|c|c|c|}
\hline \multirow{3}{*}{$\begin{array}{l}\text { Men } \\
\text { Food item }{ }^{3}\end{array}$} & & & \multicolumn{4}{|c|}{$\begin{array}{l}\text { Estimated effect on mean } \\
\text { waist circumference }\end{array}$} & \multicolumn{4}{|c|}{$\begin{array}{l}\text { Estimated effect on mean } \\
\text { hip circumference }\end{array}$} & \multicolumn{2}{|c|}{ Combined } \\
\hline & \multicolumn{2}{|c|}{$\begin{array}{l}\text { Difference in mean } \\
\text { intake } 1986-99\end{array}$} & \multicolumn{2}{|c|}{ Model I2 } & \multicolumn{2}{|c|}{ Model $2^{3}$} & \multicolumn{2}{|c|}{ Model I2 } & \multicolumn{2}{|c|}{ Model $2^{3}$} & \multirow{2}{*}{$\frac{\mathrm{I}^{2}}{\mathrm{~mm}^{6}}$} & \multirow{2}{*}{$\begin{array}{c}2^{3} \\
\mathrm{~mm}^{6}\end{array}$} \\
\hline & $/ \mathrm{mo}^{4}$ & $/ 286^{5}$ & $\mathrm{~mm}^{6}$ & $\mathrm{P}^{7}$ & $\mathrm{~mm}^{6}$ & $P^{7}$ & $\mathrm{~mm}^{6}$ & $p^{7}$ & $\mathrm{~mm}^{6}$ & $p^{7}$ & & \\
\hline beer, $4 \%$ alcohol & 1.0 & $97 \%$ & 1.41 & 0.35 & 0.26 & 0.75 & -0.63 & 0.48 & -1.03 & 0.48 & -2.04 & -1.29 \\
\hline bread, crisp & -15.3 & $-28 \%$ & 1.21 & 0.01 & 1.10 & 0.01 & 0.76 & 0.62 & 0.56 & 0.79 & -0.45 & -0.54 \\
\hline $\begin{array}{l}\text { cream/crème fr } \beta \text { iche/sour } \\
\text { cream }\end{array}$ & 1.4 & $48 \%$ & 0.41 & 0.62 & 0.33 & 0.58 & 1.98 & $<.01$ & 1.62 & $<.01$ & 1.57 & 1.29 \\
\hline fruit soups/fruit creams & -0.9 & $-25 \%$ & 0.56 & 0.73 & 0.11 & 0.76 & -0.26 & 0.31 & -0.24 & 0.29 & -0.82 & -0.35 \\
\hline hamburger & 1.0 & $68 \%$ & 2.65 & $<.01$ & 1.93 & 0.02 & 0.75 & 0.03 & 0.61 & 0.03 & -1.90 & -1.32 \\
\hline milk, I.5\% fat & 21.0 & $403 \%$ & -1.20 & 0.70 & -0.76 & 0.70 & 2.95 & $<.01$ & 2.67 & $<.01$ & 4.15 & 3.43 \\
\hline milk, $3 \%$ fat & -30.3 & $-81 \%$ & $-1.4 \mid$ & 0.80 & -1.58 & 0.73 & 1.85 & 0.01 & 1.19 & 0.02 & 3.26 & 2.77 \\
\hline oil, cooking & 7.3 & $557 \%$ & -1.65 & 0.71 & -1.45 & 0.65 & 2.68 & 0.35 & 1.80 & 0.56 & 4.33 & 3.25 \\
\hline oil, dressing & 1.8 & $97 \%$ & -0.14 & 0.78 & -0.37 & 0.69 & 0.33 & 0.99 & 0.03 & 0.99 & 0.47 & 0.40 \\
\hline pasta & 3.7 & $110 \%$ & -0.90 & 0.02 & $<.01$ & 0.10 & 1.93 & 0.01 & 1.59 & 0.02 & 2.83 & 1.59 \\
\hline $\begin{array}{l}\text { potato chips/popcorn/salted } \\
\text { nuts }\end{array}$ & 1.6 & $146 \%$ & 1.65 & 0.64 & 1.23 & 0.71 & 0.64 & 0.96 & 0.43 & 0.90 & -1.02 & -0.81 \\
\hline potatoes, French fried & 1.2 & $96 \%$ & -0.42 & 0.91 & -1.17 & 0.66 & -0.70 & 0.58 & -0.89 & 0.44 & -0.28 & 0.29 \\
\hline soft drinks & 3.9 & $114 \%$ & 0.78 & 0.21 & 0.65 & 0.16 & -0.01 & 0.25 & 0.06 & 0.38 & -0.79 & -0.59 \\
\hline sugar/honey in tea/coffee & -24.0 & $-44 \%$ & 0.67 & 0.77 & 0.97 & 0.68 & 1.19 & 0.25 & 0.94 & 0.56 & 0.52 & -0.03 \\
\hline wine & 0.8 & $65 \%$ & 0.25 & $<.01$ & -0.34 & $<.01$ & 0.53 & 0.03 & 0.48 & 0.13 & 0.28 & 0.82 \\
\hline
\end{tabular}

'Estimate of total effect on diabetes risk: Differences in mean hip-circumferences (negatively associated with DM) - Differences in mean waistcircumferences (positively associated with DM)

2 Model I: regression of change in mean reported food frequency on waist/hip circumference adjusted for BMI, age and survey-year.

3 Model 2: all variables are adjusted for BMI, age, survey-year, smoking-status (never/ex-/current), level of reported physical activity (lower/higher), educational level (primary school/secondary school/college), level of reported alcohol (quartiles) intake as well as interaction between smoking and low physical activity, smoking and high alcohol intake, low physical activity and high alcohol intake.

${ }^{4}$ number of reported intakes per month

${ }^{5}$ relative changes in \% of mean reported intake 1986

${ }^{6}$ estimated net effects of trends in reported intakes on mean waist/hip circumference.

${ }^{7}$ probabilities that partial regression coefficients for different levels of intake are equal to zero at $95 \%$ level 


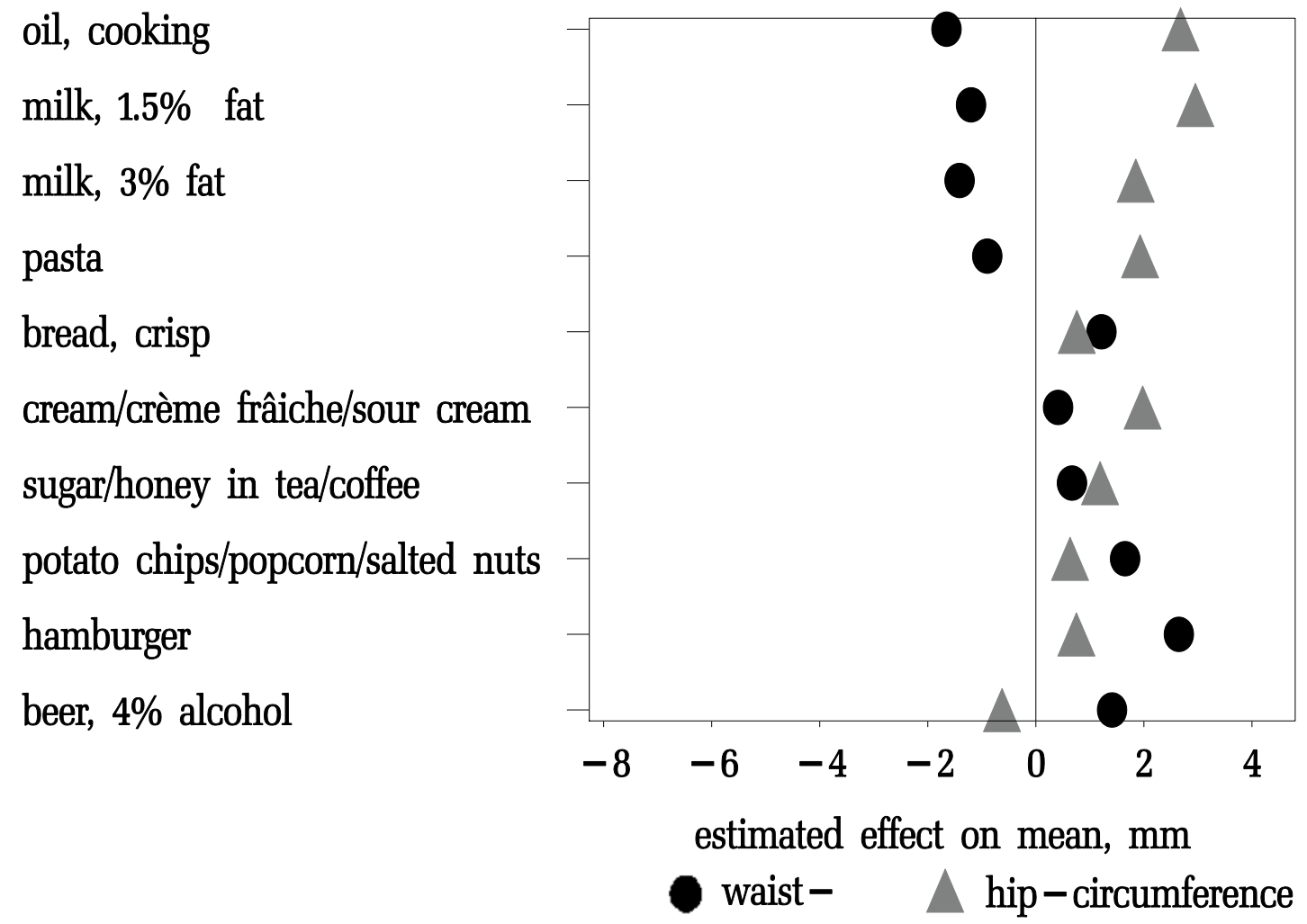

\section{Figure 3}

Estimated effect of time trends in reported food intake 1986-1999 on average waist- and hip-circumference in men. 10 items with the largest estimated effect on distribution of body fat in men. Sort order is the sum of effects from largest reduction to highest increase of risk for diabetes. The underlying associations between food intake and waist- and hip-circumferences were adjusted for age, body-mass and survey year (model I)

Most changes in mean reported intake are small, $80 \%$ ranging between one and four intakes per month. Some results apparently contradict each other from a biological point of view. For example, a lower intake of 3\% fat milk and increased use of cream were both associated with an increase in hip circumference even after adjustment for lifestyle-variables. This highlights the marker-value of reported food intake, indicating the presence of unknown or inadequately measured causative factors that are disregarded by converting reported intake of foods into estimated nutrient intake.

Only few of the underlying associations reached statistical significance reflecting the fact that reported frequency of food intake is a weak predictor of waist- and hip circumference compared to covariates such as BMI and age. The lower number of items on the food frequency question- naire in 1990 might have introduced a bias in the estimated associations between reported intake and circumferences. However, adjustment for survey year should remove systematic errors. Moreover, when comparing level-specific associations between survey-years we did not find more differences than expected by chance.

\section{Conclusion}

A mechanistic interpretation of our results would suggest an association between fat intake and abdominal obesity. Increased use of convenience foods (hamburgers, French fried potatoes), generally considered as markers of a diet high in fatty acids, was associated with an increase in WC. A number of time trends associated with a reduction of WC (less 3\% fat milk, more vegetable oil) mark a reduced intake of saturated fatty acids. The latter findings are in accordance with reports that highlight the importance of 
fat quality rather than total amount of dietary fat, although the question of the role of fat intake in the causation of obesity, diabetes and cardiovascular disease is still unresolved [36-42].

Further, our results support evidence suggesting that a diet high in low-fat dairy products and low in fast food and soft drinks is associated with smaller gains in BMI and waist circumference $[17,43,44]$. Previous findings of a negative association between intake of potatoes and WC [45] could not be confirmed in our population.

In this study, reported food intake is interpreted as marker for a general lifestyle. Any intervention targeted at individuals defined as high risk by the findings in this study, would therefore have to simultaneously aim at these lifestyle factors, rather than only try to modify consumption of a selected food item.

\section{Abbreviations}

BMI body mass index

FFQ food frequency questionnaire

\section{HC hip circumference}

MONICA Monitoring of Trends and Determinants in Cardiovascular Disease[27,28]

WC waist circumference

\section{Competing interests}

The author(s) declare that they have no competing interests.

\section{Authors' contributions}

BK was responsible for the design of the study, performed the statistical analysis and drafted the manuscript. ME contributed in its design and contributed to the manuscript. HS contributed to design and statistical analysis. IJ participated in data collection and validation. GH participated in data collection and validation and contributed to the manuscript. BL participated in study design, data analysis, writing of the manuscript and to the securing of funding. All authors read and approved the final manuscript.

\section{Additional material}

\section{Additional File 1}

List of items on food-frequency questionnaires. Complete list of all items on food frequency questionnaires in 1986. 1990, 1994 and 1999. Click here for file

[http://www.biomedcentral.com/content/supplementary/14752891-5-34-S1.doc]

\section{Acknowledgements}

We are indebted to a previous anonymous reviewer for valuable suggestions. This study was supported by the Joint Committee of the local county councils of Jämtland, Norrbotten, Västernorrland, Västerbotten ("Visare Norr") and a grant by Norrbottensakademin. The Northern Sweden MONICA Project has been supported by grants from Norrbotten and Västerbotten counties, by the Joint Committee of Northern Sweden Health Care Region, the Swedish Public Health, the Swedish Medical Research Council (MFR), the Heart and Chest Foundation, the Stroke Fund, King Gustaf V's and Queen Victoria's foundation, Vårdalstiftelsen, the Social Sciences Research Council.

None of the above-mentioned funding bodies had any influence on study design, data collection, analysis or interpretation; writing or decision to submit the manuscript for publication.

\section{References}

I. Tuomilehto J, Lindstrom J, Eriksson JG, Valle TT, Hamalainen $H$, llanne-Parikka P, Keinanen-Kiukaanniemi S, Laakso M, Louheranta A, Rastas M, Salminen V, Uusitupa M: Prevention of type 2 diabetes mellitus by changes in lifestyle among subjects with impaired glucose tolerance. In N Engl J Med Volume 344. Issue 18 United States ; 2001:1343-1350.

2. Ratner RE: An update on the Diabetes Prevention Program. Endocr Pract 2006, I 2 Suppl I:20-24.

3. Serra-Majem L, Roman B, Estruch R: Scientific evidence of interventions using the Mediterranean diet: a systematic review. Nutr Rev 2006, 64(2 Pt 2):S27-47.

4. Seidell JC, Perusse L, Despres JP, Bouchard C: Waist and hip circumferences have independent and opposite effects on cardiovascular disease risk factors: the Quebec Family Study. In Am J Clin Nutr Volume 74. Issue 3 United States ; 2001:3I5-321.

5. Bosello $O$, Zamboni M: Visceral obesity and metabolic syndrome. In Obes Rev Volume I. Issue I England ; 2000:47-56.

6. Rankinen T, Kim SY, Perusse L, Despres JP, Bouchard C: The prediction of abdominal visceral fat level from body composition and anthropometry: ROC analysis. In Int J Obes Relat Metab Disord Volume 23. Issue 8 England ; 1999:80I-809.

7. Janssen I, Katzmarzyk PT, Ross R: Waist circumference and not body mass index explains obesity-related health risk. Am J Clin Nutr 2004, 79(3):379-384.

8. Wang Y, Rimm EB, Stampfer MJ, Willett WC, Hu FB: Comparison of abdominal adiposity and overall obesity in predicting risk of type 2 diabetes among men. Am J Clin Nutr 2005, 8I(3):555-563.

9. Sanchez-Castillo CP, Velasquez-Monroy O, Lara-Esqueda A, Berber A, Sepulveda J, Tapia-Conyer R, James WP: Diabetes and hypertension increases in a society with abdominal obesity: results of the Mexican National Health Survey 2000. Public Health Nutr 2005, 8(I):53-60.

10. Wildman RP, Gu D, Reynolds K, Duan X, Wu X, He J: Are waist circumference and body mass index independently associated with cardiovascular disease risk in Chinese adults? Am J Clin Nutr 2005, 82(6): I | 95- I 202

II. Seidell JC, Han TS, Feskens EJ, Lean ME: Narrow hips and broad waist circumferences independently contribute to increased risk of non-insulin-dependent diabetes mellitus. J Intern Med 1997, 242(5):40I-406.

12. Lissner L, Bjorkelund C, Heitmann BL, Seidell JC, Bengtsson C: Larger hip circumference independently predicts health and longevity in a Swedish female cohort. Obes Res 200I, 9(10):644-646.

13. Snijder MB, Dekker JM, Visser M, Bouter LM, Stehouwer CD, Kostense PJ, Yudkin JS, Heine RJ, Nijpels G, Seidell JC: Associations of hip and thigh circumferences independent of waist circumference with the incidence of type 2 diabetes: the Hoorn Study. Am J Clin Nutr 2003, 77(5): I I92-I I 97.

14. Snijder MB, Zimmet PZ, Visser M, Dekker JM, Seidell JC, Shaw JE: Independent and opposite associations of waist and hip circumferences with diabetes, hypertension and dyslipidemia: the AusDiab Study. Int J Obes Relat Metab Disord 2004, 28(3):402-409. 
15. Esmaillzadeh A, Mirmiran P, Azadbakht L, Amiri P, Azizi F: Independent and inverse association of hip circumference with metabolic risk factors in Tehranian adult men. Prev Med 2006, 42(5):354-357.

16. Samaras K, Campbell LV: The non-genetic determinants of central adiposity. In Int J Obes Relat Metab Disord Volume 2I. Issue 10 England ; 1997:839-845.

17. Newby PK, Muller D, Hallfrisch J, Qiao N, Andres R, Tucker KL: Dietary patterns and changes in body mass index and waist circumference in adults. Am J Clin Nutr 2003, 77(6): |4I 17-1425.

18. Kahn HS, Tatham LM, Heath CW Jr.: Contrasting factors associated with abdominal and peripheral weight gain among adult women. Int J Obes Relat Metab Disord I997, 2 I (10):903-9II.

19. Harding $A H$, Williams DE, Hennings $\mathrm{SH}$, Mitchell J, Wareham NJ: Is the association between dietary fat intake and insulin resistance modified by physical activity? Metabolism 200I, 50(10): I I86-II92.

20. Janssen I, Katzmarzyk PT, Ross R, Leon AS, Skinner JS, Rao DC, Wilmore JH, Rankinen T, Bouchard C: Fitness alters the associations of BMI and waist circumference with total and abdominal fat. Obes Res 2004, I 2(3):525-537.

21. Holcomb CA, Heim DL, Loughin TM: Physical activity minimizes the association of body fatness with abdominal obesity in white, premenopausal women: results from the Third National Health and Nutrition Examination Survey. J Am Diet Assoc 2004, I 04(I 2): | 859- I 862.

22. Koh-Banerjee P, Chu NF, Spiegelman D, Rosner B, Colditz G, Willett $\mathrm{W}$, Rimm E: Prospective study of the association of changes in dietary intake, physical activity, alcohol consumption, and smoking with 9-y gain in waist circumference among 16587 US men. Am J Clin Nutr 2003, 78(4):7। 9-727.

23. Eliasson M, Lindahl B, Lundberg $V$, Stegmayr $B$ : No increase in the prevalence of known diabetes between 1986 and 1999 in subjects 25-64 years of age in northern Sweden. In Diabet Med Volume 19. Issue 10 England ; 2002:874-880.

24. Eliasson M, Lindahl B, Lundberg V, Stegmayr B: Diabetes and obesity in Northern Sweden: occurrence and risk factors for stroke and myocardial infarction. Scand J Public Health 2003, Suppl 61:70-77.

25. Lindahl B, Stegmayr B, Johansson I, Weinehall L, Hallmans G: Trends in lifestyle $1986-99$ in a 25- to 64-year-old population of the Northern Sweden MONICA project. Scand J Public Health 2003, Suppl 6I:3I-37.

26. Krachler B, Eliasson MC, Johansson I, Hallmans G, Lindahl B: Trends in food intakes in Swedish adults 1986-1999: findings from the Northern Sweden MONICA (Monitoring of Trends and Determinants in Cardiovascular Disease) Study. Public Health Nutr 2005, 8(6):628-635.

27. Tunstall-Pedoe H, Vanuzzo D, Hobbs M, Mahonen M, Cepaitis Z, Kuulasmaa K, Keil U: Estimation of contribution of changes in coronary care to improving survival, event rates, and coronary heart disease mortality across the WHO MONICA Project populations. Lancet 2000, 355(9205):688-700.

28. Kuulasmaa K, Tunstall-Pedoe H, Dobson A, Fortmann S, Sans S, Tolonen $\mathrm{H}$, Evans A, Ferrario M, Tuomilehto J: Estimation of contribution of changes in classic risk factors to trends in coronaryevent rates across the WHO MONICA Project populations. Lancet 2000, 355(9205):675-687.

29. Stegmayr $B$, Lundberg $V$, Asplund $K$ : The events registration and survey procedures in the Northern Sweden MONICA Project. Scand J Public Health 2003, Suppl 61:9-17.

30. Eriksson M, Stegmayr B, Lundberg V: MONICA quality assessments. Scand J Public Health 2003, Suppl 6I:25-30.

3I. Johansson I, Hallmans G, Wikman A, Biessy C, Riboli E, Kaaks R: Validation and calibration of food-frequency questionnaire measurements in the Northern Sweden Health and Disease cohort. In Public Health Nutr Volume 5. Issue 3 England ; 2002:487-496.

32. Gonzalez CA, Pera G, Quiros JR, Lasheras C, Tormo MJ, Rodriguez M, Navarro C, Martinez C, Dorronsoro M, Chirlaque MD, Beguiristain JM, Barricarte A, Amiano P, Agudo A: Types of fat intake and body mass index in a Mediterranean country. In Public Health Nutr Volume 3. Issue 3 England ; 2000:329-336.

33. Samaras K, Kelly PJ, Chiano MN, Arden N, Spector TD, Campbell LV: Genes versus environment. The relationship between die- tary fat and total and central abdominal fat. In Diabetes Care Volume 21. Issue 12 United States ; 1998:2069-2076.

34. Wirfalt E, Hedblad B, Gullberg B, Mattisson I, Andren C, Rosander U, Janzon L, Berglund G: Food patterns and components of the metabolic syndrome in men and women: a cross-sectional study within the Malmo Diet and Cancer cohort. In Am J Epidemiol Volume 154. Issue 12 United States ; 200 I:I I50-I I59.

35. Hu FB, Rimm EB, Stampfer MJ, Ascherio A, Spiegelman D, Willett WC: Prospective study of major dietary patterns and risk of coronary heart disease in men. In Am J Clin Nutr Volume 72. Issue 4 United States ; 2000:912-921.

36. Willett WC: Dietary fat plays a major role in obesity: no. In Obes Rev Volume 3. Issue 2 England ; 2002:59-68.

37. Astrup A: Dietary fat is a major player in obesity--but not the only one. In Obes Rev Volume 3. Issue 2 England ; 2002:57-58.

38. Marshall JA, Bessesen DH: Dietary fat and the development of type 2 diabetes. In Diabetes Care Volume 25. Issue 3 United States ; 2002:620-622

39. Feskens EJ: Can diabetes be prevented by vegetable fat? In Diabetes Care Volume 24. Issue 9 United States ; 2001:1517-1518.

40. Hu FB, Stampfer MJ, Manson JE, Ascherio A, Colditz GA, Speizer FE, Hennekens $\mathrm{CH}$, Willett WC: Dietary saturated fats and their food sources in relation to the risk of coronary heart disease in women. In Am J Clin Nutr Volume 70. Issue 6 United States ; 1999:1001-1008.

4I. Meyer KA, Kushi LH, Jacobs DR Jr., Folsom AR: Dietary fat and incidence of type 2 diabetes in older lowa women. In Diabetes Care Volume 24. Issue 9 United States ; 200 I:1528-1535.

42. Vessby B: Dietary fat and insulin action in humans. In Br J Nutr Volume 83 Suppl I. Issue Suppl I England ; 2000:S9I-6.

43. Newby PK, Muller D, Hallfrisch J, Andres R, Tucker KL: Food patterns measured by factor analysis and anthropometric changes in adults. Am J Clin Nutr 2004, 80(2):504-5I3.

44. Drapeau V, Provencher V, Lemieux S, Despres JP, Bouchard C, Tremblay A: Do 6-y changes in eating behaviors predict changes in body weight? Results from the Quebec Family Study. Int J Obes Relat Metab Disord 2003, 27(7):808-8I4.

45. Halkjaer J, Sorensen TI, Tjonneland A, Togo P, Holst C, Heitmann BL: Food and drinking patterns as predictors of 6-year BMIadjusted changes in waist circumference. Br J Nutr 2004, 92(4):735-748.

\section{Publish with Biomed Central and every scientist can read your work free of charge}

"BioMed Central will be the most significant development for disseminating the results of biomedical research in our lifetime. "

Sir Paul Nurse, Cancer Research UK

Your research papers will be:

- available free of charge to the entire biomedical community

- peer reviewed and published immediately upon acceptance

- cited in PubMed and archived on PubMed Central

- yours - you keep the copyright 